\title{
Red shape, blue shape: political ideology influences the social perception of body shape
}

\author{
María Alejandra Quirós-Ramírez (D) ${ }^{1,3 凶}$, Stephan Streuber ${ }^{2,3}$ \& Michael J. Black ${ }^{1}$
}

Political elections have a profound impact on individuals and societies. Optimal voting is thought to be based on informed and deliberate decisions yet, it has been demonstrated that the outcomes of political elections are biased by the perception of candidates' facial features and the stereotypical traits voters attribute to these. Interestingly, political identification changes the attribution of stereotypical traits from facial features. This study explores whether the perception of body shape elicits similar effects on political trait attribution and whether these associations can be visualized. In Experiment 1, ratings of 3D body shapes were used to model the relationship between perception of 3D body shape and the attribution of political traits such as 'Republican', 'Democrat', or 'Leader'. This allowed analyzing and visualizing the mental representations of stereotypical 3D body shapes associated with each political trait. Experiment 2 was designed to test whether political identification of the raters affected the attribution of political traits to different types of body shapes. The results show that humans attribute political traits to the same body shapes differently depending on their own political preference. These findings show that our judgments of others are influenced by their body shape and our own political views. Such judgments have potential political and societal implications.

\footnotetext{
${ }^{1}$ Max Planck Institute for Intelligent Systems, Tübingen, Germany. ${ }^{2}$ University of Konstanz, Konstanz, Germany. ${ }^{3}$ These authors contributed equally: María Alejandra Quirós-Ramírez, Stephan Streuber. ${ }^{凶}$ email: alejandra.quiros@tuebingen.mpg.de
} 


\section{Introduction}

n democracies, political candidates are elected to represent and enforce the citizens' will. Rationally, voting behavior should rely on information about a candidate's political agenda, such as their positions on employment, taxes, or immigration. However, research has found that voting behavior is not only affected by the candidates' ideology but also by their physical traits, for example, their facial appearance (Ballew and Todorov, 2007; Berggren et al., 2017; Carpinella et al., 2016; Goren et al., 2005; Hall et al., 2010; Olivola and Todorov, 2010). It has been demonstrated that character traits inferred from the facial features of political candidates could predict the outcome of the U.S. congressional elections (Ballew and Todorov, 2007; Carpinella and Johnson, 2016; Goren et al., 2005; Olivola and Todorov, 2010). Interestingly, political identification of the voters affected the perception of faces of political candidates (Young et al., 2014; Caruso et al., 2009). Voters whose political identity matched that of a political candidate perceived their face as more favorable (Young et al., 2014; Caruso et al., 2009). While previous studies investigated the relationship between facial appearance and trait inference, relatively little attention has been devoted to studying the relationship between perception of body shape and the attribution of political traits. In this article, we investigated whether, similar to faces, bodies also elicit perceptions of political traits such as "Republican", "Democrat", "Liberal", "Socialist", or "Aggressive" and whether an individual's political identification affects how they attribute political traits to body shape.

Since ancient times, humans have conjectured that there is a relationship between the physical body and the character or temperament of a person (Chou, 2014; Kapla, 2007; Ross, 1928). In modern times, the German psychiatrist Ernst Kretschmer attempted to correlate body type with personality traits and mental illness (Kretschmer, 1922). Similarly, the American psychologist William Sheldon developed a taxonomy to relate body shape and character traits. Sheldon proposed three prototypical "somatotype" body shapes: endomorph, mesomorph, and ectomorph, each representing a distinct character trait profile (Sheldon et al., 2001). While the idea of predicting character from physical characteristics has been widely discredited, the somatotype body shapes have been used to study trait inference and to reveal social biases in body perception (Brodsky, 1954; Lerner, 1969; Ryckman et al., 1989; Strongman and Hart, 1968). More recent research focuses on the effect of preceived body shape and specific body-shape-related parameters (e.g., stature, weight, body mass index, waist-to-hip ratio, waist-to-chest ratio) on the perception of emotions (McDonnell 2009), person identity (Piryankova et al., 2014; Thaler et al., 2018; Thaler et al., 2018), attractiveness (Legenbauer et al., 2009; Streuber et al., 2016; Tovée et al., 2002; Van Driel, 2014), self-esteem (Furnham et al., 2002), gender (K. L. Johnson et al., 2012), and personality (Hu et al., 2018).

It is known that trait inference from appearance relies on automatic and involuntary processes (Oosterhof and Todorov, 2008) and that it affects many aspects of everyday life such as employment (Krieger, 1995; Sczesny et al., 2006), medical treatment (LêCook et al., 2012; Van Ryn and Saha, 2011), decisions in court trials (Rachlinski et al., 2014), and even political election results (Ballew and Todorov, 2007; Berggren et al., 2017; Goren et al., 2005; Hall et al., 2010; Olivola and Todorov, 2010). Previous work proposes that the cognitive system matches visual input about a person to a stereotypical mental representation of a specific social category (Brinkman et al., 2017; Dotsch et al., 2011; Freeman and Ambady, 2011). A stereotype representation refers to the most typical instance of a specific social category. For example, when assessing whether a face looks happy, the cognitive system compares this face to the stereotypical representations of happy and unhappy faces and selects the best match (Mangini and Biederman, 2004). Hence, uncovering and visualizing the stereotypical representations is crucial for our understanding of how individuals make social judgments based on visual features.

Previous research has used various statistical methods to visualize mental representations of faces, for example, relying on the perceptual judgments of random variation of stimuli (Dotsch et al., 2011). The goal is to model the mathematical relationship between stimuli presented and the responses of the observers, allowing the investigation of which stimulus properties drive the judgments (Jack et al., 2018). Most relevant here, statistical modeling has been combined with $3 \mathrm{D}$ face models to visualize mental representations of stereotype faces (Oosterhof and Todorov, 2008). Face models are trained from 3D laser scans of faces and represent each face as a point in multidimensional face space. Relating perceptual face ratings to face space parameters has made it possible to reconstruct synthetic faces that vary in social trait dimensions such as 'trustworthiness' and 'dominance'. While statistical face models facilitate research on social face perception, such studies do not yet exist in the domain of social body perception. The articulated $3 \mathrm{D}$ human body is strictly more complex than the face (since it includes the face) and high-quality statistical models have only recently become available (Loper et al., 2015) due to advancements in machine learning and body scanning technologies. Our hypothesis is that the same kinds of biases observed in viewing faces apply to the perception of human body shape as well. Recent work has shown that body shape can be predicted from linguistic physical descriptions of body shape (Streuber et al., 2016) and that people infer personality traits from body shape (Hu et al., 2018). Here, we use a statistical 3D body model and linearly regress between $3 \mathrm{D}$ body shapes and perceptual ratings to visualize and analyze stereotypes of political traits and how such stereotypes vary with political identification.

We conducted two online experiments to investigate, model, and visualize the metric relationship between 3D body shape and the attribution of political traits. Experiment 1 was designed to test whether body shape elicits the attribution of political traits similar to faces. Experiment 2 was designed to test whether the political identification of the raters affects the attribution of political traits to body shape. The study protocol was approved by the ethics research committee at the University of Tübingen and has been performed in accordance with the Declaration of Helsinki. Participants in both experiments gave informed consent before participating in the study. The use of linear regression, perceptual ratings of body shapes, and a statistical body model allowed us to analyze and visualize the mental representations of body shape (stereotype bodies) associated with different political traits for raters of different political identifications.

\section{Experiment 1-Associations between body shape and perception of political traits}

In this experiment, we tested the hypothesis that body shape elicits the attribution of political traits. To do this, we modeled the relationship between $3 \mathrm{D}$ body shapes and political trait ratings. If body shape elicits the attribution of political traits, we should be able to automatically predict 3D body shape from political trait ratings and vice versa using our model. This model allows us to quantify the relationship between $3 \mathrm{D}$ body shape and political trait ratings and allows us to visualize the mental stereotype representations associated with each political trait.

\section{Materials and methods}

Political traits. The list of political traits assessed in this experiment consisted of 25 descriptors. The first two descriptors 
Table 1 List of political trait descriptors ordered alphabetically.

$\begin{array}{lllll} & & & \\ \text { Aggressive } & \text { Big } & \text { Built } & \text { Caring } & \text { Compassionate } \\ \text { Democrat } & \text { Educated } & \text { Ignorant } & \text { Independent } & \text { Intelligent } \\ \text { Leader } & \text { Liberal } & \text { Long torso } & \text { Passive } & \text { Patriotic } \\ \text { Poor } & \text { Powerful } & \text { Republican } & \text { Rich } & \text { Socialist } \\ \text { Stubborn } & \text { Sympathetic } & \text { Tall } & \text { Traditional } & \text { Trustworthy }\end{array}$

The bold items represent the main political categories. The words in italics are used to evaluate the quality of the ratings and are not used for modeling.

represented the binary categories of the United States political party system ('Republican' and 'Democrat'). The remaining 23 descriptors were words associated with these two categories and were collected in a survey prior to the main experiment. The complete list of political trait descriptors is shown in Table 1. In addition, five body shape terms were added as control terms (in italics in Table 1).

Participants. Four hundred ninety-two participants (mean age 34.3 years \pm 8.08 SD, 227 male) participated in Experiment 1. All participants were recruited in the online platform Amazon Mechanical Turk (AMT). The participation was restricted to residents of the USA. The experiment took, on average, $19 \mathrm{~min}$ to complete and participation was rewarded monetarily. Following the Body Talk methodology (Streuber et al., 2016), we randomly split the participants into two groups to separately observe male or female body shapes. The first group (245 participants, mean age $32.7 \pm 4.4 \mathrm{SD}, 127$ male) observed images of male bodies while the second group (247 participants, mean age $35.9 \pm$ $3.85 \mathrm{SD}, 100$ male) observed images of female bodies. The number of participants was selected to collect approximately 15 ratings per body shape from different raters, given that previous research on crowdsourcing perceptual ratings of body shape showed that 10 to 15 raters per body shape produced good quality modeling results (Streuber et al., 2016).

Stimuli. Two hundred fifty-six random body shapes (128 female and 128 male) were created using the statistical body model named SMPL. SMPL is a statistical 3D body model learned from high-resolution body scans (Loper et al., 2015). In this model, the human body is represented as a three-dimensional template (mean) mesh with 6890 vertices. There is a separate model for male and for female bodies. Body shape is defined as the deviation from the mean mesh computed using Principal Component Analysis (PCA) on a corpus of thousands of 3D body scans. For this study, we have used the first eight principal shape components for the male and female models downloaded from the SMPL website (SMPL). These eight principal shape components account for $96.56 \%$ of the body shape variations in the training corpus of 3D body scans of SMPL. Body shape is represented as a linear combination of deviations from the mean mesh. Synthetic bodies were generated by randomly sampling from the Gaussian distribution over the shape dimensions given by SMPL's PCA space. The synthetic bodies were posed identically using the mean pose of the training population of the SMPL model for men and women, respectively. Each body was rendered in Maya (Autodesk, 2015) to create the stimuli. The same camera model and parameters were used for all the renderings. Examples of the rendered stimuli can be seen in Fig. 1.

Procedure. In order to participate in the experiment, participants were required to pass an English language test first. Before starting the experiment, participants read the instructions and gave their consent to participate in the experiment. Each participant rated eight different synthetic bodies using all 30 terms.
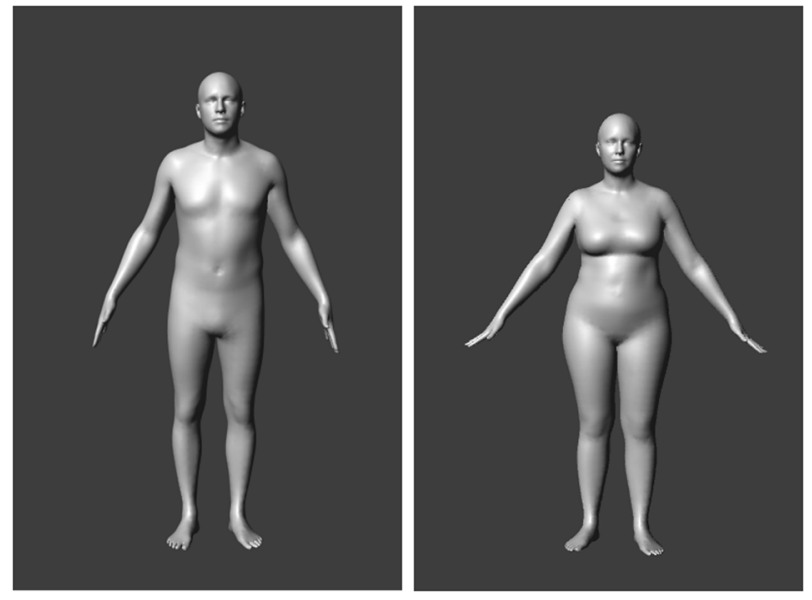

Fig. 1 Stimuli body shapes. Samples of rendered random synthetic male and female bodies.

The bodies were shown in a random order, one at a time, together with one single descriptor. Thus, in total, each participant rated 240 pairs of a random body and a random political trait. Participants were not informed of the repetition of the bodies. The rating task consisted of evaluating, on a 5-point Likert scale, how much each term applies to the body in the image. The scale ranged from 'does not apply at all' to 'completely applies'.

To ensure the quality of the data, and account for the possibility that inattention or fatigue led to errors, we included catch trials to monitor the quality of the responses of the participants. In addition to the eight stimuli bodies, we included two catch trial bodies: a demonstrably big body and a demonstrably slim body. These catch trial bodies were presented randomly to the participants as part of the experiment, together with the shape descriptors "big", "long torso", "pear shaped", "tall", and "built". Each participant rated in total ten pairs of a catch trial body and a random shape descriptor. A participant's data were excluded if the participant rated the big catch trial body shape with a score lower than 3 for the word "big" or the slim catch trial body shape with a score higher than 3 for the word "big". As a result of this check, 66 participants who rated male body shapes and 75 participants who rated female body shapes were removed from the analysis.

At the end of the body-rating phase, participants were asked to fill out a demographic questionnaire (see Table 2), and to press the final 'submit' button to record their participation. They were automatically rewarded through the AMT interface within $24 \mathrm{~h}$ of their participation in the study.

The data collection for male and female bodies was conducted on different days in two consecutive trials. In the first trial, we only collected ratings of male body shapes $(N=245$, mean age $32.7 \pm 4.4 \mathrm{SD})$ and in the second trial, we only collected ratings of female body shapes $(N=247$, mean age $35.9 \pm 3.85 \mathrm{SD})$. 


\section{Table 2 Demographic questionnaire for Experiments 1 and 2.}

Q1 Where were you born?

Q2 How many years did you live (have you lived) there?

Q3 Where do you live?

Q4 How many years have you lived there?

Q5 What is your gender?

Q6 How old are you?

Q7 What is your weight? (pounds)

Q8 What is your height? (feet inch)

Q9 What is your ethnicity?

Q10 What is your zip code?

Q11 What is your political affiliation?

Q12 If elections were held today, whom would you vote for?

Q13 Comments [optional]

\section{Analysis and results}

Modeling the mapping from political trait ratings to $3 D$ body shape. To test whether body shape elicits the perception of 25 political traits, we fit a linear function from political trait ratings to $3 \mathrm{D}$ body shape parameters using a similar approach as Body Talk (Streuber et al., 2016). We trained one linear function per gender.

Each of the 128 body shapes $y_{i}$ (per gender) presented in Experiment 1 is defined by a shape vector $y_{\mathrm{i}}=\left[\beta_{1}, \ldots, \beta_{8}\right]^{T}$, where $\beta_{c=1,2, \ldots, 8}$ represent the linear coefficients that constitute the specific body shape $y_{i}$ in SMPL's multidimensional PCA space. The ratings of each rater $k$ and body $i$ are represented in the rating vector $\left[r_{1, i, k}, \ldots, r_{W, i, k}\right]^{T}$, where $W=25$ political trait descriptors. Because individual ratings are noisy, we averaged the ratings for each body per descriptor resulting in 128 rating vectors $x_{i}=\left[\bar{r}_{1, i}, \ldots, \bar{r}_{W, i}\right]^{T}$. The resulting rating matrix is:

$$
\mathrm{X}=\left[\begin{array}{cc}
1 & \mathrm{x}_{1}^{\mathrm{T}} \\
\vdots & \vdots \\
1 & \mathrm{x}_{128}^{\mathrm{T}}
\end{array}\right]
$$

and our set of bodies is denoted by $Y=\left[y_{1}, \cdots, y_{128}\right]^{T}$ having one body per row. Assuming a linear relationship between political trait ratings and body shape coefficients,

$$
Y=X B+\epsilon
$$

where $\in$ represents independent and identically distributed Gaussian noise, we solve the regression coefficients $B$ using least squares.

The procedure was repeated for ratings of male and female bodies resulting in two trait-to-shape models, one per gender. Each model takes as an input a new rating vector $x$ in order to predict body shape coefficients $y$, which define body shape in the multidimensional SMPL shape space.

To evaluate the metric accuracy of both models, we used a leave-one-out cross-validation (Wong, 2015) approach on the training data. We trained each of the two models 128 times. Each time a model was trained, we left out one of the 128 body shapes and the respective ratings and trained the model with the remaining 127 bodies. Then we used this model to predict a body shape from the left-out ratings. The resulting 128 predicted bodies were then compared to the original 128 bodies by calculating the reconstruction error. Reconstruction error (RE) is defined as the mean absolute distance between each vertex in the mesh of the original, true, body and the corresponding vertex in the mesh of the predicted body from the ratings. RE was calculated for each of the 128 bodies per gender. We calculated the mean $\mathrm{RE}$ for the male $(\mathrm{RE}=15.41 \mathrm{~mm} ; \mathrm{SD}=7.05 \mathrm{~mm})$ and female model $(\mathrm{RE}=14.49 \mathrm{~mm}$; SD $6.43 \mathrm{~mm}$ ) and compared it to the $\mathrm{RE}$ of a random male model $(\mathrm{RE}=27.94 \mathrm{~mm}$, $\mathrm{SD}=13.04 \mathrm{~mm})$ and a random male model $(\mathrm{RE}=26.49 \mathrm{~mm}$, $\mathrm{SD}=11.93 \mathrm{~mm}$ ), where $\mathrm{RE}$ was calculated from a random mapping between bodies and ratings. To test the significance of the differences we conducted two independent $t$-tests on the differences between the $128 \mathrm{RE}$ scores obtained from the trait-toshape model and the RE scores obtained from the random models. We found highly significant differences between the RE scores obtained from the male trait-shape-model and the RE scores obtained from the random male model $(t=11.38$; $p=4.49 \times 10^{-21}$ ) and the differences between the RE scores obtained from the female trait-shape-model and the RE scores obtained from the random female model (and $t=11.51$, $\left.p=6.36 \times 10^{-25}\right)$. This supports our hypothesis of a linear association between body shape and political trait ratings and that body shape can be predicted from political trait ratings alone using a statistical model.

Reconstructing stereotypical $3 D$ bodies. We used the male and female trait-to-shape model in order to visualize stereotype bodies for each political trait. The SMPL model allows reconstructing and visualizing a body shape simply by setting its principal shape components to numeric parameters. The male and female traitto-shape model outputs eight shape parameters predicted from a specific rating vector. To visualize a specific political trait, we set the score of this descriptor to a value of 5 , which represents the maximum rating of a specific trait. We then condition on this specific trait and, using the learned correlations among traits, estimate the expected values of the remaining traits. The conditioning procedure is the same as in Body Talk (Streuber et al., 2016). Each trait word elicited a distinct 3D stereotype body. The resulting stereotype bodies are shown in Fig. 2. These 3D stereotype bodies are a visual representation of the collective mental image participants associated with each political trait.

Relating political traits with physical traits. Our results revealed a strong association between body shape and political trait ratings. Previous research has shown a strong association between body shape and physical trait ratings (Streuber et al. 2016) and personality traits (Hu et al., 2018). This leads us to posit that there may also be an association between political trait ratings and physical trait ratings. In order to test this hypothesis, we used the physical trait rating data from Body Talk (Streuber et al., 2016) and calculated a covariance matrix between political and physical trait ratings. As expected, we found significant correlations between ratings of political traits and ratings of physical traits (see Fig. 3). We found, for example, that the male Republican stereotype body was described as 'Heavyset', 'Stocky', 'Sturdy', and un-'Fit', whereas the male Democrat stereotype body was described as being 'Masculine', 'Lean', and 'Fit'. This analysis also allowed us to directly compare differences in male and female stereotypes in terms of physical traits. For instance, the political trait 'Republican' was positively correlated with 'Tall' for male bodies but negatively correlated with 'Tall' for female bodies. In the same vein, 'Leader' was positively correlated with 'Big' for male bodies, but negatively correlated with female bodies. That indicates, that political traits are assigned to bodies differently, depending on whether the body is male or female.

The results of Experiment 1 show that there is a correlation between human body shapes and the attribution of traits. However, it is not clear whether the political ideology of the observer is correlated with this relationship. With this question in mind, we performed Experiment 2. 


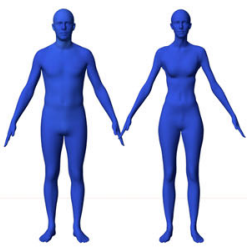

democrat

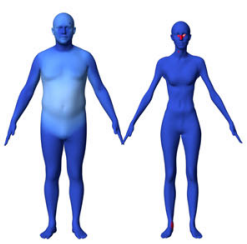

socialist

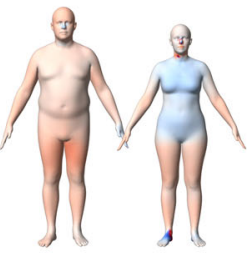

caring

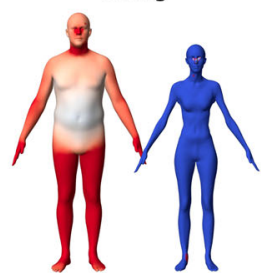

rich

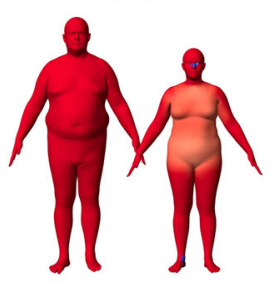

conservative

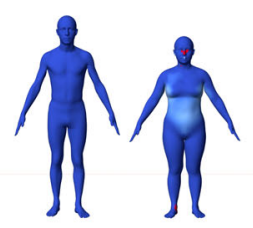

weak

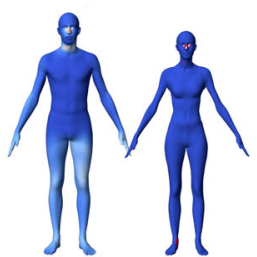

educated

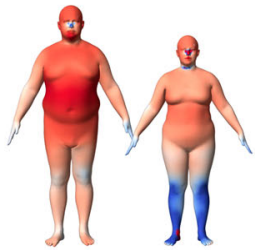

irrational

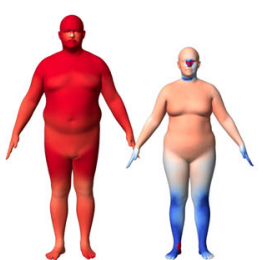

stubborn

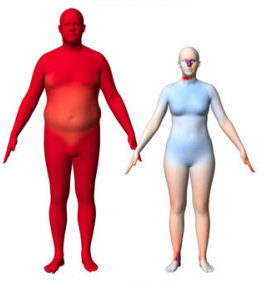

patriotic

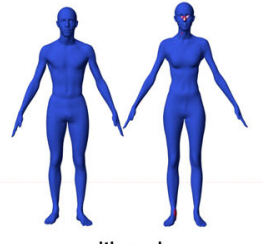

liberal

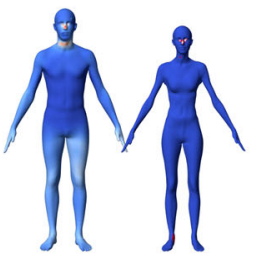

intelligent

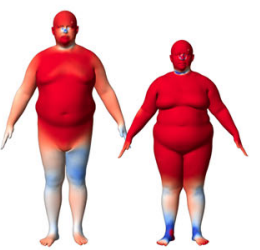

ignorant

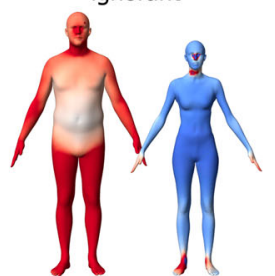

leader

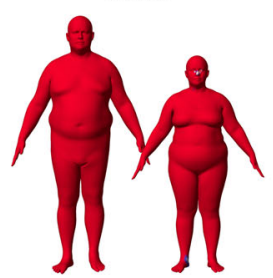

southern
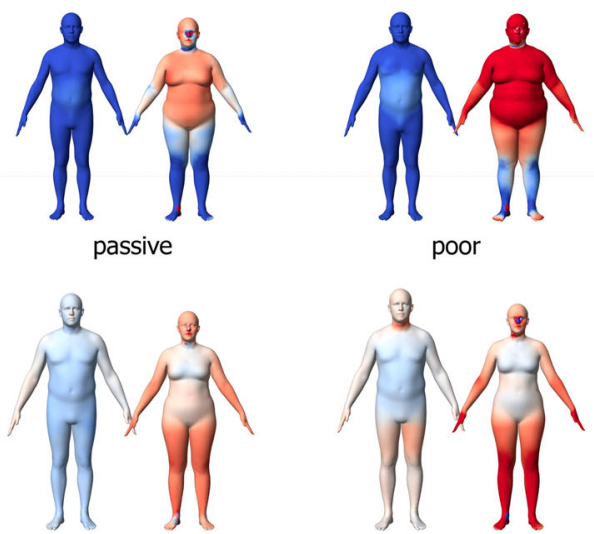

sympathetic

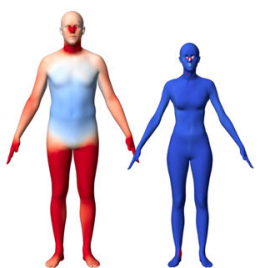

trustworthy

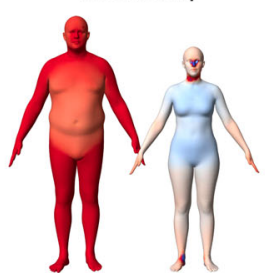

traditional

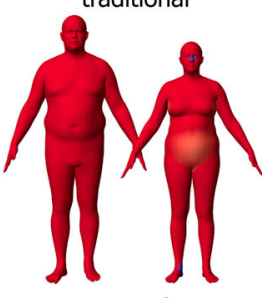

aggressive

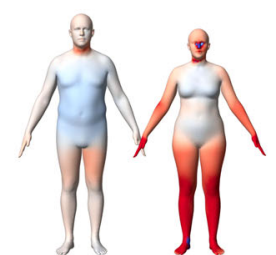

compassionate

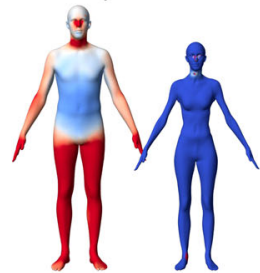

independent

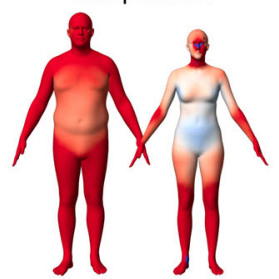

powerful

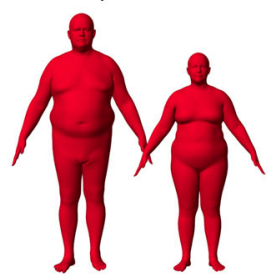

republican

Fig. 2 Visualization of stereotype bodies. Each body pair illustrates the mental representation associated with different political traits for male and female bodies. Blue color indicates a geometric closeness to the Democrat stereotype, while red color represents geometric closeness to the Republican stereotype.

\section{Experiment 2-Does political orientation affect the associations between body shape and the perception of political traits?}

Experiment 2 was designed to test whether political identification of the viewer affects the mapping between body shape and trait perception. In order to test this, we asked a new set of participants to rate a new set of body shapes using political and physical descriptors. We also assessed the political orientation of each rater, which allowed us to categorize raters into Republican and Democrat raters. If political identification affects the perception of political traits, we would expect that participants rate identical body shapes differently depending on their own political orientation.

\section{Materials and methods}

Participants. Four hundred eighty-seven participants (mean age 34.7 years \pm 7.97 SD, 190 men) participated in Experiment 2. All participants were recruited in the online platform Amazon
Mechanical Turk (AMT). The participation was restricted to residents of the USA. The experiment took an average of 4 minutes and participation was rewarded monetarily. Participants who had already joined Experiment 1 were not allowed to take part in Experiment 2.

Stimuli. We generated the male stereotype bodies for the political traits: "Democrat", "Republican" and "Trustworthy" from the data collected in Experiment 1 (see Reconstructing the stereotypical $3 D$ bodies for details on the procedure). We also added the average male body shape from the SMPL model and included it in the stimulus set. We rendered all 4 bodies using the identical procedure as in Experiment 1 (see Fig. 4).

Rating descriptors. The following political trait descriptors were selected from descriptors used in Experiment 1: "Democrat", "Republican", "Trustworthy", and "Stubborn". We selected these descriptors because they showed a strong association with body 


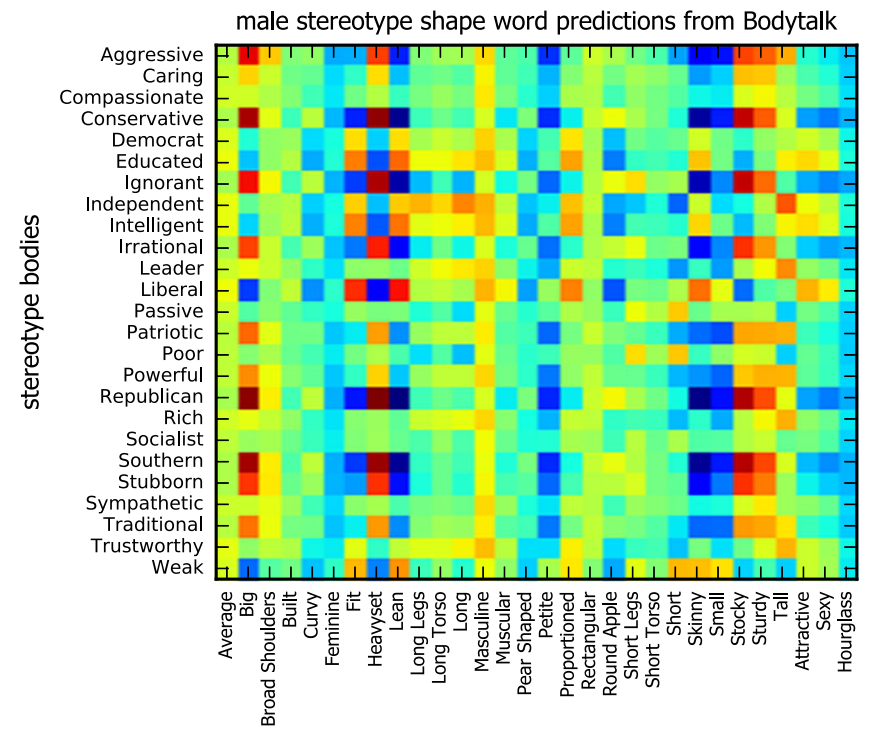

shape words

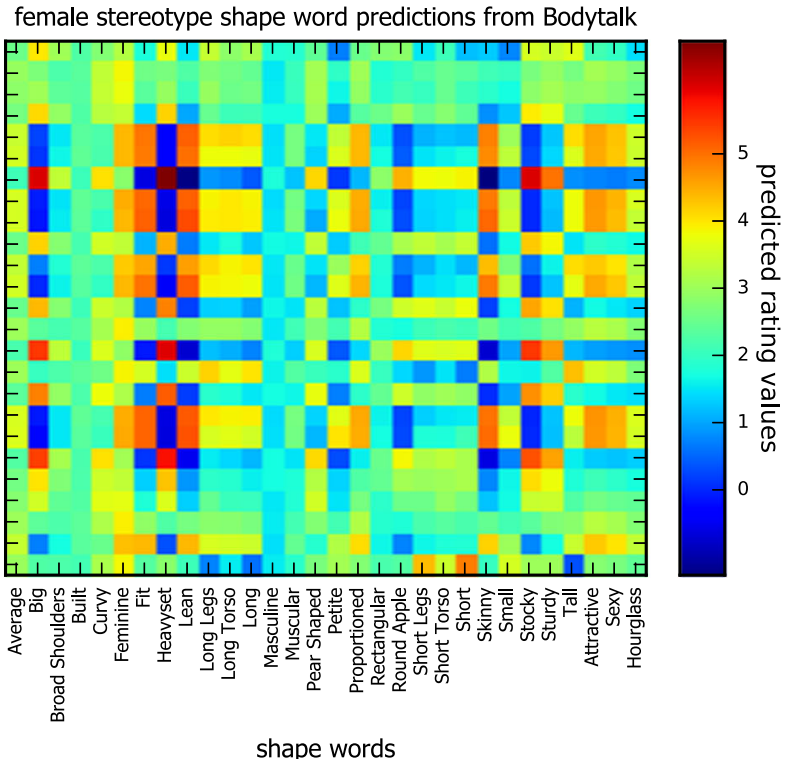

shape words

Fig. 3 Semantic relationship between political and phyisical traits. Predictions of body shape descriptions for each stereotype body using the Body Talk model (Streuber et al., 2016).
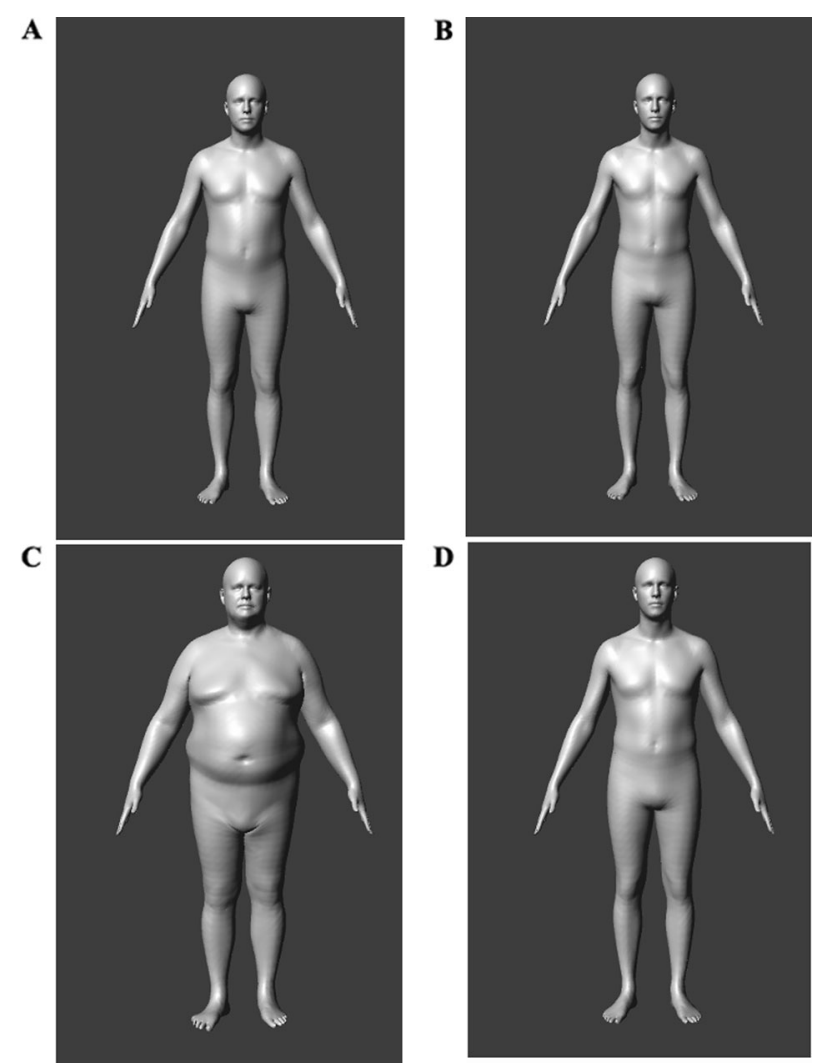

Fig. 4 Stimuli for experiment 2. A Average male body from the SMPL model. B-D Stereotype bodies generated from the data in Experiment 1 for "Democrat", "Republican", and "Trustworthy", respectively.

shape in Experiment 1. We also added two physical trait descriptors: "Heavy" and "Fit", as controls, resulting in six descriptors.

Procedure. Experiment 2 was conducted after the analysis of Experiment 1 was completed. Before starting the experiment, participants read the instructions and gave their consent to participate in the experiment. Participants were asked to rate the four body shapes using the six descriptors resulting in a total of 24 pairs of random synthetic bodies and random terms. After, participants filled out the demographic questionnaire. To finalize the task, participants had to press the 'submit' button to record their participation. Participants were automatically rewarded through the AMT interface within $24 \mathrm{~h}$ of their participation in the study.

In order to test whether participants performed the task correctly, and to account for potential inattention or fatigue, we evaluated the ratings given to the bodies using the physical shape descriptors ("Heavy" and "Fit"). A participant's data were excluded if the participant rated the "Democrat" stereotype body-which is a demonstrably slim body-with the term "Heavy", or the "Republican" stereotype body- which is a demonstrably heavy body-using the term "Fit", with a value higher than 3 on the Likert-scale. In these cases, we assumed that the participant did not understand the task or did not carry out the evaluation conscientiously. As a result of this procedure, the data of 86 participants were removed from the analysis.

Analysis and results. The goal of this experiment was to determine whether political identification affects the perception of political traits from body shape. We first performed a manipulation check to test if the stimuli generated for this experiment elicited the perception of the corresponding political traits.

Manipulation check. In order to test whether the stereotype body shapes generated from the data in Experiment 1 elicited the corresponding political trait perceptions (e.g., the 'Republican' stereotype body should elicit high ratings for the 'Republican' descriptor), we conducted an analysis on the ratings collected in Experiment 2. We found that the mean ratings of each descriptor were significantly higher than the average ratings. Independent $t$ tests were conducted for each trait and each stereotype body in order to evaluate the significance of these differences. The resulting $t$-values were Bonferroni corrected to account for multiple comparisons. The results are visualized in Fig. 5. All traits were perceived as significantly different from the mean, 

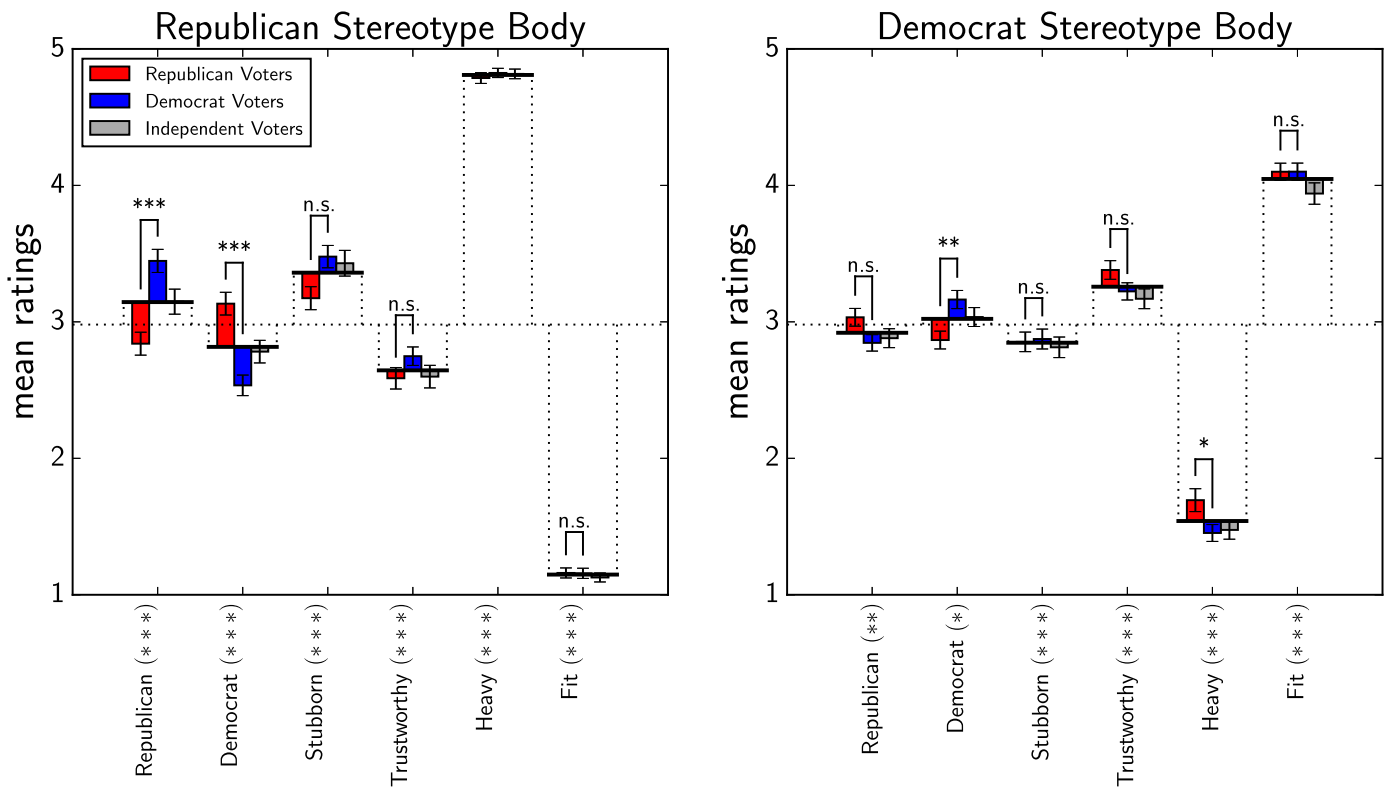

Fig. 5 Mean ratings for the Republican stereotype body (left graph) and the Democrat stereotype body (right graph). The $y$-axis shows the mean rating value on the 5-point Likert scale ranging from 1: "strongly disagree" to 5: "strongly agree". The $x$-axis shows the trait used to rate the body shape. The red bars show the ratings of the Republican group and the blue bars show the ratings of the Democrat group. Gray bars show the ratings of the Independent group. The bold horizontal line indicates the mean of all ratings collected in Experiment 2. Significant differences are indicated: ${ }^{\star}(p<0.05) ;{ }^{\star \star}(p<0.01) ;$ ${ }^{\star \star \star}(p<0.001)$ next to the $x$-axis label for each trait, n.s. indicates no significant difference.

\begin{tabular}{|c|c|c|c|c|c|c|c|c|}
\hline & \multicolumn{4}{|c|}{ Republican stereotype } & \multicolumn{4}{|c|}{ Democrat stereotype } \\
\hline & $t$ & $p$ & Mean & SD & $t$ & $p$ & Mean & SD \\
\hline Republican & 4.04 & $7.02 \times 10^{-5}$ & $\begin{array}{l}r: 2.84 \\
d: 3.44\end{array}$ & $\begin{array}{l}r: 1.05 \\
d: 1.06\end{array}$ & -2.42 & 0.01 & $\begin{array}{l}r: 3.03 \\
d: 2.84\end{array}$ & $\begin{array}{l}r: 0.81 \\
d: 0.75\end{array}$ \\
\hline Stubborn & 2.07 & 0.03 & $\begin{array}{l}r: 3.17 \\
d: 3.47\end{array}$ & $\begin{array}{l}r: 1.06 \\
d: 1.03\end{array}$ & 0.22 & 0.81 & $\begin{array}{l}r: 2.85 \\
d: 2.87\end{array}$ & $\begin{array}{l}r: 0.90 \\
d: 0.91\end{array}$ \\
\hline Trustworthy & 1.27 & 0.20 & $\begin{array}{l}r: 2.58 \\
d: 2.74\end{array}$ & $\begin{array}{l}r: 0.99 \\
d: 0.85\end{array}$ & -1.93 & 0.05 & $\begin{array}{l}r: 3.38 \\
d: 3.22\end{array}$ & $\begin{array}{l}r: 0.86 \\
d: 0.79\end{array}$ \\
\hline Heavy & 0.58 & 0.55 & $\begin{array}{l}r: 4.78 \\
d: 4.82\end{array}$ & $\begin{array}{l}r: 0.49 \\
d: 0.42\end{array}$ & -2.75 & 0.006 & $\begin{array}{l}r: 1.69 \\
d: 1.45\end{array}$ & $\begin{array}{l}r: 1.05 \\
d: 0.77\end{array}$ \\
\hline Fit & -0.04 & 0.96 & $\begin{array}{l}r: 1.16 \\
d: 1.15\end{array}$ & $\begin{array}{l}r: 0.46 \\
d: 0.46\end{array}$ & 0.008 & 0.99 & $\begin{array}{l}r: 4.1 \\
d: 4.10\end{array}$ & $\begin{array}{l}r: 0.78 \\
d: 0.79\end{array}$ \\
\hline
\end{tabular}

indicating that the stereotype bodies generated in Experiment 1 induced the correct trait perceptions as expected.

The effect of political identification on the perception of political traits. We analyzed whether participants rated the same bodies differently depending on their own political affiliation. To test this, we categorized the rating data according to the participants' political affiliation, based on their answer to question 11 in the demographic's questionnaire: "What is your political affiliation?". Participants could choose one of the following options: "Democrat", "Republican", "Independent", "None", "Other". We selected the data of participants who chose the options "Democrat" $(n=159)$, "Republican" $(n=75)$, or "Independent" $(n=142)$ and split them into three groups, respectively. Given that there was no pre-screening for political affiliation, the sample size was chosen to secure enough participants in these three groups of interest. From now on, these are called the "Democrat" group, "Republican" group, and "Independent" group. We performed independent $t$-tests to compare the ratings between the "Democrat" and "Republican" groups for each stereotype body. The $p$-values were Bonferroni corrected. Results of the $t$-tests are reported in Table 3 and visualized in Fig. 5. There are highly significant differences in the ratings depending on the participants' political identification. Republican raters rated the Republican stereotype body as less 'Republican' than the Democrat raters did. On the other hand, Democrat raters rated the Democrat stereotype body as more 'Democrat' compared to the Republican raters. The effect of other characteristics of the participants, besides political affiliation, on the ratings was ruled out by performing t-tests on the differences in height, weight, and gender between the "Republican" and "Democrat" participants. No significant difference was found for height $(t=0.44, p=0.65)$, weight $(t=1.29, p=0.19)$, or gender $(t=-1.19, p=0.23)$. These results support our hypothesis that 

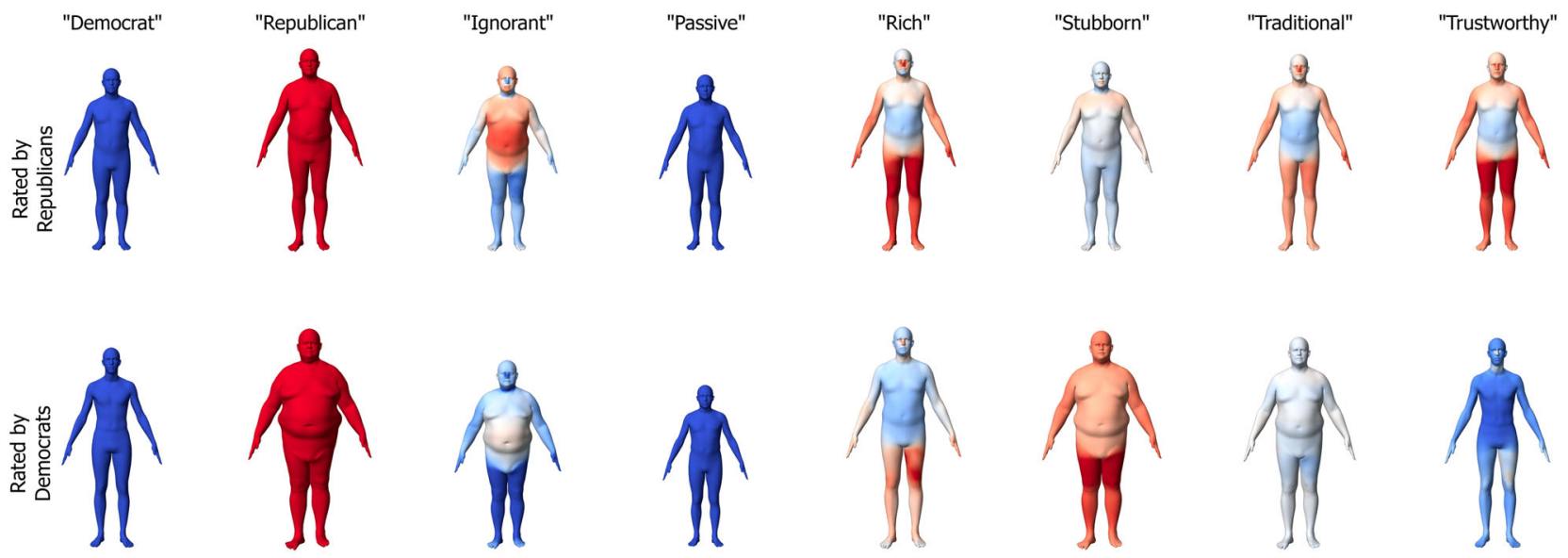

Fig. 6 Stereotype bodies as seen by Republican and Democrat groups. Blue color indicates a geometric closeness to the Democrat stereotype, while red color represents geometric closeness to the Republican stereotype, per group.

political affiliation affects the perception of political traits from the body shape.

Visualizing stereotype bodies for people who identify as Democrat or Republican. Based on these results, we split the dataset collected in Experiment 1 into two groups based on the political affiliation of the participants (Q11 answers "Republican" or "Democrat), fit a linear function per group exactly as in Experiment 1 , and visualized the stereotype bodies separately for each group, following the 3D body visualization procedure explained in Experiment 1. We augment the features of each stereotype to facilitate the visual exploration of the differences per group by setting the score of the target trait score in the model learned in Experiment 1 to 8 instead of 5. A subset of the resulting stereotype bodies can be seen in Fig. 6 (the full set of stereotype bodies can be found in Supplemental Figs. 1 and 2). Here, blue colors indicate geometric closeness to the Democrat stereotype, while red colors represent geometric closeness to the Republican stereotype. A visual inspection reveals geometric differences in the stereotype bodies generated per group for each trait. Republicans' mental representation of "Republican" was skinnier than Democrats' mental representation of "Republican" and vice versa.

\section{General discussion}

In this article, we examined the metric relationship between 3D body shape and the perception of political traits, and its modulation by political identification of the observer. The results of Experiment 1 show that observers use body shape information to make inferences about the political traits of a person when no other information is available. These first impressions affect not only how we attribute traits to other people, but possibly also how we interact with those people, and how we perceive and evaluate them in political elections. Research has shown that first impressions from faces affect individuals' social life, and here we show that similar perceptual and cognitive mechanisms exist for body shape. The effect of body appearance on trait perception is not surprising, since bodies usually co-occur with faces (Yovel and O'Toole, 2016) and, in many cases, bodies are the more salient cue, for instance, when recognizing the gender of a person from the distance (K. L. Johnson et al., 2012). Furthermore, overall face features might correlate with body features qualifying both sources of visual information as effective cues for making trait attributions. Politicians (and non-politicians) might possess intuitive knowledge about the importance of visual body appearance on trait perception, and actively work to optimize their visual appearance to make better impressions, for example, looking more trustworthy or caring. It has been shown that visual appearance management significantly impacts voting behavior and electoral outcomes (Banducci et al., 2008; Buckley et al., 2007).

It is important to highlight the gender differences in trait perception found in our results when automatically labeling the 3D stereotype bodies obtained from Experiment 1 using physical shape descriptors. For females only, the shape descriptors 'Fit and 'Lean' were positively correlated with the female stereotype bodies for the traits 'Rich', 'Socialist', 'Leader', and 'Trustworthy' while inversely correlated with 'Passive', 'Poor', 'Republican', and 'Southern'. Gender differences in stereotype perception are in line with research on leadership and fitness. For instance, facial adiposity leads to the perception of lower leadership abilities (Re et al., 2012; Re and Perrett, 2014). Our results suggest that this effect may be true for females in the case of overall body adiposity. Also, previous studies have demonstrated that there is a gender disparity in leadership perception, due to the social roles of males and females, in which female leaders need to demonstrate both sensitivity and strength to be perceived as effective (S. K. Johnson et al., 2008). Perhaps, due to similar social role expectations in females, fitness and leanness are also expected in successful females. The research of Chiao et al., 2008 demonstrated that voters are more likely to vote for female candidates who appear more attractive, and previous work (Streuber et al., 2016) shows that females who are described as 'fit' and 'lean' score high in the ratings for the 'attractive' descriptor.

The results of Experiment 2 show that participants rate the 3D stereotype bodies significantly higher on the corresponding traits: participants rated the 'Republican' stereotype body as 'Republican' and the 'Democrat' stereotype as 'Democrat', validating the 3D-body shapes generated from Experiment 1, which depict the stereotype bodies for the political trait words. Second, the ratings were significantly different depending on the political affiliation of the participant, Republican versus Democrat. For instance, participants who belong to the Democrat group rated the 'Republican' stereotype body as significantly more 'Republican' and significantly less 'Democrat' compared to participants with Republican identification: Republican raters rated the 'Republican' stereotype body as less 'Republican' than the Democrat raters did. On the other hand, Democrat raters rated the Democrat stereotype body as more 'Democrat' compared to the Republican raters. Interestingly, participants rated the 'Republican' stereotype body as less 'Trustworthy' and more 'Stubborn' irrespective of their political identity. The perception of physical body properties such as 'heavy' or 'fit' was partially affected by 
political identification. Taken together, these results confirm our hypothesis that political identity affects the perception of traits. While this effect has been demonstrated for faces (Young et al., 2014), we believe that this is the first evidence that political identification affects the perception of body shape.

Self-identified Republicans have a mental representation of Republicans that is skinnier than self-identified Democrats' mental representation of Republicans. This suggests that people attribute more positive body shape characteristics, for example, thinness, to their own peer group. In a similar way, some positive traits, such as trustworthiness, generated stereotype bodies more similar to the Democrat stereotype for Democrat raters and more similar to the Republican stereotype body for Republican raters, as seen in Fig. 6. The opposite effect was found for some negative traits such as 'stubborn'. In-group favoritism (Dasgupta, 2004) could explain the attribution of positive traits to body shapes that look more similar to the stereotype body of the preferred group. In-group favoritism could also explain why self-identified Republicans perceive the Republican stereotype as less 'Republican' and as more 'Democrat', considering how the 'Republican' stereotype was perceived by the participants as less trustworthy (the desired attribute) and more stubborn (a non-desired attribute). Given these general negative perceptions on the 'Republican' stereotype body, it is not surprising that self-identified Democrats rate this body as significantly more 'Republican' than 'Democrat', in line with the research findings on out-group prejudice (Fedor, 2014). However, other traits cannot be explained by these effects. For instance, both Republican and Democrat raters, associated the word "passive" with a skinny and small body shape, and the word "rich" with a rather tall body shape.

Our findings can help raise awareness of unconscious biases in trait perception from body shape among the electorate. Awareness of the social biases induced by face and body features may help people make more informed and better voting decisions. The results and visualization methods may increase awareness that body shape and our unconscious biases may support discrimination beyond politics, in areas such as healthcare, the legal system, and education.

\section{Conclusion}

There is a mathematical relationship between body shape and perception of political traits that is affected by an observer's political views. This study suggests a novel methodology to study the perception of such traits from 3D body shapes. These findings have not only social but also political implications: electoral decisions may be affected by a candidate's body shape. Raising awareness of this bias in the electorate may help voters make better conscious and informed choices.

\section{Data availability}

Data, code, and materials used in the analysis will be available upon request from the corresponding author.

Received: 14 October 2020; Accepted: 18 May 2021;

Published online: 18 June 2021

\section{References}

AMT Amazon mechanical turk. http://www.mturk.com. Accessed: 2016-2017

Ballew CC, Todorov A (2007) Predicting political elections from rapid and unreflective face judgments. Proc Natl Acad Sci USA https://doi.org/10.1073/ pnas. 0705435104

Banducci SA, Karp JA, Thrasher M, Rallings C (2008) Ballot photographs as cues in low-information elections. Polit Psychol https://doi.org/10.1111/j.14679221.2008.00672.x
Berggren N, Jordahl H, Poutvaara P (2017) The right look: conservative politicians look better and voters reward it. J Public Econ https://doi.org/10.1016/j. jpubeco.2016.12.008

Brinkman L, Todorov A, Dotsch R (2017) Visualising mental representations: a primer on noise-based reverse correlation in social psychology. Eur Rev Soc Psychol. https://doi.org/10.1080/10463283.2017.1381469

Brodsky CM (1954) A study of norms for body form-behavior relationship. Anthropol Quart 27(4):91-101

Buckley F, Collins N, Reidy T (2007) Ballot paper photographs and low-information elections in Ireland. Politics https://doi.org/10.1111/j.1467-9256.2007.00297.x

Carpinella CM, Hehman E, Freeman JB, Johnson KL (2016) The gendered face of Partisan politics: consequences of facial sex typicality for vote choice. Polit Commun https://doi.org/10.1080/10584609.2014.958260

Carpinella CM, Johnson KL (2016) Visual political communication: the impact of facial cues from social constituencies to personal pocketbooks. Soc Personal Psychol Compass https://doi.org/10.1111/spc3.12249

Caruso EM, Mead NL, Balcetis E (2009) Political partisanship influences perception of biracial candidates' skin tone. Proc Natl Acad Sci USA https://doi.org/ $10.1073 /$ pnas.0905362106

Chiao JY, Bowman NE, Gill H (2008) The political gender gap: gender bias in facial inferences that predict voting behavior. PLoS ONE https://doi.org/10.1371/ journal.pone. 0003666

Chou ES (2014) Chinese medicine and healing: an illustrated history. China J https://doi.org/10.1093/jhmas/jru015

Dasgupta N (2004) Implicit ingroup favoritism, outgroup favoritism, and their behavioral manifestations. Soc Justice Res https://doi.org/10.1023/B: SORE.0000027407.70241.15

Dotsch R., Wigboldus DHJ, van Knippenberg A (2011) Biased allocation of faces to social categories. J Pers Soc Psychol https://doi.org/10.1037/a0023026

Fedor C-G. (2014) Stereotypes and prejudice in the perception of the "Other." Proc Soc Behav https://doi.org/10.1016/j.sbspro.2014.08.257

Freeman JB, Ambady N (2011) A dynamic interactive theory of person construal. Psychol Rev https://doi.org/10.1037/a0022327

Furnham A, Badmin N, Sneade I (2002) Body image dissatisfaction: gender differences in eating attitudes, self-esteem, and reasons for exercise. J Psychol Interdiscipl Appl https://doi.org/10.1080/00223980209604820

Goren A, Hall CC, Mandisodza AN, Todorov A (2005) Inferences of competence from faces predict election outcomes. Science https://doi.org/10.1126/ science. 1110589

Hall CC, Goren A, Chaiken S, Todorov A (2010) Shallow cues with deep effects: trait judgments from faces and voting decisions. Polit Psychol Democratic Citizenship. https://doi.org/10.1093/acprof:oso/9780195335453.003.0004

Hu Y, Parde CJ, Hill MQ, Mahmood N, O'Toole AJ (2018) First impressions of personality traits from body shapes. Psychol Sci https://doi.org/10.1177/ 0956797618799300

Jack RE, Crivelli C, Wheatley T (2018) Data-driven methods to diversify knowledge of human psychology. Trends Cogn Sci https://doi.org/10.1016/j.tics.2017.10.002

Johnson KL, Iida M, Tassinary LG (2012) Person (mis)perception: functionally biased sex categorization of bodies. Proc R Soc B https://doi.org/10.1098/ rspb.2012.2060

Johnson SK, Murphy SE, Zewdie S, Reichard RJ (2008) The strong, sensitive type: effects of gender stereotypes and leadership prototypes on the evaluation of male and female leaders. Organ Behav Hum Dec https://doi.org/10.1016/j. obhdp.2007.12.002

Kapla S (2007) Race matters: orientalism and religion, India and beyond c. 17701880. Mod Asian Stud https://doi.org/10.1017/S0026749X06002526

Kretschmer E (1922) Körperbau und Charakter. Untersuchungen zum Konstitutionsproblem und zur Lehre von den Temperamenten. Zeitschrift Für Induktive Abstammungs Und Vererbungslehre 30(1):139-144

Krieger LH (1995) The content of our categories: a cognitive bias approach to discrimination and equal employment opportunity. Stanford Law Rev https:// doi.org/10.1016/j.compstruct.2018.02.057

LêCook B, McGuire TG, Zaslavsky AM (2012) Measuring racial/ethnic disparities in health care: methods and practical issues. Health Serv Res https://doi.org/ 10.1111/j.1475-6773.2012.01387.x

Legenbauer T, Vocks S, Schäfer C, Schütt-Strömel S, Hiller W, Wagner C, Vögele C (2009) Preference for attractiveness and thinness in a partner: Influence of internalization of the thin ideal and shape/weight dissatisfaction in heterosexual women, heterosexual men, lesbians, and gay men. Body Image https:// doi.org/10.1016/j.bodyim.2009.04.002

Lerner RM (1969) Some female stereotypes of male body build-behavior relations. Percept Motor Skills 28(2):363-366

Loper M, Mahmood N, Romero J, Pons-moll G, Black MJ (2015) SMPL: a skinned multi-person linear model. ACM Trans Graphics https://doi.org/10.1145/ 2816795.2818013

Mangini MC, Biederman I (2004) Making the ineffable explicit: estimating the information employed for face classifications. Cogn Sci https://doi.org/ 10.1016/j.cogsci.2003.11.004 
McDonnell R, Jörg S, McHugh J, Newell FN, O'Sullivan C (2009) Investigating the role of body shape on the perception of emotion. ACM T Appl Percept https://doi.org/10.1145/1577755.1577757

Olivola CY, Todorov A (2010) Elected in 100 milliseconds: appearance-based trait inferences and voting. J Nonverbal Behav https://doi.org/10.1007/s10919009-0082-1

Oosterhof NN, Todorov A (2008) The functional basis of face evaluation. Proc Natl Acad Sci USA https://doi.org/10.1073/pnas.0805664105

Piryankova IV, Stefanucci JK, Romero J, De La Rosa S, Black MJ, Mohler BJ (2014) Can i recognize my body's weight? The influence of shape and texture on the perception of self. ACM T Appl Percept https://doi.org/10.1145/2641568

Rachlinski J, Lynn S, Andrewj J, Guthrie C (2014) Does unconscious racial bias affect trial judges? Notre Dame Law Rev https://doi.org/10.1525/sp.2007.54.1.23.

Re DE, Dzhelyova M, Holzleitner IJ, Tigue CC, Feinberg DR, Perrett DI (2012) Apparent height and body mass index influence perceived leadership ability in three-dimensional faces. Perception https://doi.org/10.1068/p7342

Re DE, Perrett DI (2014). The effects of facial adiposity on attractiveness and perceived leadership ability. Q J Exp Psychol https://doi.org/10.1080/ 17470218.2013.825635

Ross WD (ed) (1928) The works of Aristotle translated into English. Clarendon Press, Cambridge

Ryckman RM, Robbins MA, Kaczor LM, Gold JA (1989) Male and female raters' stereotyping of male and female physiques. Pers Soc Psychol B 15(2):244-251

Sczesny S, Spreemann S, Stahlberg D (2006) Masculine=competent? Physical appearance and sex as sources of gender-stereotypic attributions. Swiss J Psychol https://doi.org/10.1024/1421-0185.65.1.15

Sheldon WH, Stevens SS, Tucker WB (2001) The varieties of human physique. Harper, New York

SMPL: a skinned multi-person linear model. https://smpl.is.tue.mpg.de/. Accessed: 2016-2017

Streuber S, Quiros-Ramirez MA, Hill MQ, Hahn CA, Zuffi S, O'Toole A, Black MJ (2016) Body talk: crowdshaping realistic 3D avatars with words. ACM Trans Graphics https://doi.org/10.1145/2897824.2925981

Strongman KT, Hart CJ (1968) Stereotyped reactions to body build. Psychol Rep 23:1175-1178

Thaler A, Geuss MN, Mölbert SC, Giel KE, Streuber S, Romero J, Black MJ, Mohler BJ (2018) Body size estimation of self and others in females varying in BMI. PLoS ONE https://doi.org/10.1371/journal.pone.0192152

Thaler A, Piryankova I, Stefanucci JK, Pujades S, de La Rosa S, Streuber S, Romero J, Black MJ, Mohler BJ (2018) Visual perception and evaluation of photorealistic self-avatars from $3 \mathrm{D}$ body scans in males and females. Front ICT https://doi.org/10.3389/fict.2018.00018

Tovée MJ, Hancock PJB, Mahmoodi S, Singleton BRR, Cornelissen PL (2002) Human female attractiveness: waveform analysis of body shape. Proc R Soc B https://doi.org/10.1098/rspb.2002.2133

Van Driel MF (2014) Re: Penis size interacts with body shape and height to influence male attractiveness. Eur Urol https://doi.org/10.1016/j.eururo.2013.12.031

Van Ryn M, Saha S (2011) Exploring unconscious bias in disparities research and medical education. JAMA https://doi.org/10.1001/jama.2011.1275

Wong TT (2015) Performance evaluation of classification algorithms by $k$-fold and leave-one-out cross validation. Pattern Recogn https://doi.org/10.1016/j. patcog.2015.03.009
Young AI, Ratner KG, Fazio RH (2014) Political attitudes bias the mental representation of a Presidential Candidate's face. Psychol Sci https://doi.org/ $10.1177 / 0956797613510717$

Yovel G, O'Toole AJ (2016) Recognizing people in motion. Trends Cogn Sci https://doi.org/10.1016/j.tics.2016.02.005

\section{Acknowledgements}

M.J.B. thanks E. Rachlin, A. Weiss, M. Loper, and D. Hirshberg for discussions about politics and body shape. M.A.Q.R. acknowledges O.S.S.Q. and C.I.S.Q. for their insights and encouragement. S.S. acknowledges the DFG Centre of Excellence 2117 "Centre for the Advanced Study of Collective Behavior" (ID:422037984).

\section{Funding}

Open Access funding enabled and organized by Projekt DEAL.

\section{Competing interests}

The authors declare competing financial interests with the patents WO2017129827A1 and WO2016207311A1. M.J.B. has received research gift funds from Intel, NVIDIA, Adobe, Facebook, and Amazon. While M.J.B. is a part-time employee of Amazon, this research was performed solely at, and funded solely by the Max Planck Institute. M.J.B. has financial interests in Amazon, Datagen Technologies, and Meshcapade GmbH.

\section{Additional information}

Supplementary information The online version contains supplementary material available at https://doi.org/10.1057/s41599-021-00817-7.

Correspondence and requests for materials should be addressed to M.A.Q-R.

Reprints and permission information is available at http://www.nature.com/reprints

Publisher's note Springer Nature remains neutral with regard to jurisdictional claims in published maps and institutional affiliations.

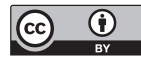

Open Access This article is licensed under a Creative Commons Attribution 4.0 International License, which permits use, sharing, adaptation, distribution and reproduction in any medium or format, as long as you give appropriate credit to the original author(s) and the source, provide a link to the Creative Commons license, and indicate if changes were made. The images or other third party material in this article are included in the article's Creative Commons license, unless indicated otherwise in a credit line to the material. If material is not included in the article's Creative Commons license and your intended use is not permitted by statutory regulation or exceeds the permitted use, you will need to obtain permission directly from the copyright holder. To view a copy of this license, visit http://creativecommons.org/ licenses/by/4.0/.

(C) The Author(s) 2021 